\title{
The Active Role of Servant Leadership to Improve Performance of employees
}

\author{
Manal Abdel Hamid Abdel Majid ${ }^{1}$, Haider jare mahsen ${ }^{2}$ \\ \{Manal.abdulmajeed@stu.edu.iq ${ }^{1}$, haider.jare@stu.edu.iq $\left.{ }^{2}\right\}$ \\ Technical Institute, Southern Technical University, Iraq ${ }^{1,2}$
}

\begin{abstract}
The study expressed the problem through a set of questions focused on whether there is a correlation and effect relationship between the modern leadership patterns based on a hypothetical model of 60 members as leaders and heads of departments at the University of Basra. The members are appointed from various colleges such as Arts, Administration, Economics, Education for Girls, and Law. The study considers a descriptive-analytical approach based on a questionnaire consisting of three sections. The first concerns the personal data of the respondents. The second includes servant leadership with its six dimensions represented by trust, participation in decision-making, empowerment, vision, providing guidance, and helping subordinates to Success and growth. Finally, the third deals with the performance of employees, measured by the following variables: job satisfaction, creativity, absence, and finally productivity. A statistical programme is written to justify the outcomes of this study. It is found that the orientation to servant leadership is one of the best trends as it is a new style based on positive ideas and principles that create a method of work.
\end{abstract}

Keywords: Servant leadership, performance employees, Al Basra University

\section{Introduction}

Leaders' roles have changed dramatically in the past few years, so many successful leaders have changed their ways of working, through making moving from the center of the group to its periphery, working as team members rather than leaders or managers, and becoming the new leaders They work on understanding the human behavior of individuals to direct this behavior to achieve the goals of the organization. Therefore, successful leadership is the one who works to spread the spirit of cooperation and teamwork among the workers, and it is the one who realizes the importance of raising the morale of subordinates, identifying their desires, and completing the work entrusted to them to achieve the goals Servant leadership also plays a key role in planting confidence among subordinates within the university formations and their participation in decision-making, providing guidance and helping them to grow and succeed. Finally, the research was divided into four sections. The first topic was devoted to the research methodology and deals the second topic with the theoretical aspect represented in the concept of leadership. The maid with its six dimensions, in addition to the variables of workers' performance, the third topic includes the practical aspect, and finally deals the fourth topic with the Conclusions and recommendations.

\subsection{The Study Problem}

The researchers found, through the exploratory study of the colleges under study, that there are some organizational problems related to the behavior of workers that lead to confusion as a 
result of not choosing leadership patterns that help raise the performance and efficiency of workers, but the contrary, negatively affect their performance. Among these influences is the low level of Mutual trust between superiors and subordinates because they believe that leaders prefer their interests over the interests of workers and the goals of the organization, which leads to their sacrificing the values of justice and equality, frequent complaints by subordinates about how the work is managed, feelings of dissatisfaction and anxiety, low productivity within the work environment, and thus the need appears To study the influential leadership styles, especially the servant leadership philosophy, which is one of the most prominent types of contemporary leaders, and the research problem can be diagnosed by answering the following questions:

a) To what extent can servant leadership affect organizational citizenship behavior and change the direction of employees' performance positively towards achieving the organization's goals?

b) Does the application of the servant leadership philosophy reduce the negative indicators in the organizations?

\subsection{The Study Aim}

The main objectives of the study can be identified as follows:

Recognizing the extent to which the administrative leaders practice to remove the servant leadership from the point of view of the faculty members. Evaluating the level of administrative leaders in the organizations under study concerning the application of the dimensions of servant leadership and the performance of employees Clarify the nature of the relationship and the impact between servant leadership and the performance of workers for the organizations surveyed. To present some suggestions and recommendations to the surveyed organizations about the interest in removing the effect of servant leadership on the performance of the employees. Determine whether there is an influence relationship between the dimensions of servant leadership and the performance of employees.

\subsection{The Importance of the Study}

The importance of the study comes from the importance of servant leadership as one of the patterns of its leaders capable of helping organizations to overcome their internal problems, through its policies in taking care of the interests of workers and helping them solve their problems, raising the efficiency of their performance and developing their abilities and skills, which leads to raising the efficiency of the organization's performance, which helps it Facing the challenges of the external environment and building society as a whole.

\subsection{Hypothesis of the Study}

The research is based on two main hypotheses:

a) There is a positive statistically significant correlation between servant leadership and the performance of employees at the University of Basra.

b) There is a positive and statistically significant effect of servant leadership on improving the performance of employees at the University of Basra.

\subsection{The Study Model}


The model was designed to represent the basic idea on which the study is based and to clarify the nature of the relationship between the study variables. The scheme included two main variables:

1. the independent variable $(\mathrm{x})$ is represented by servant leadership.

2. the dependent variable $(y)$ is represented by the performance of workers.

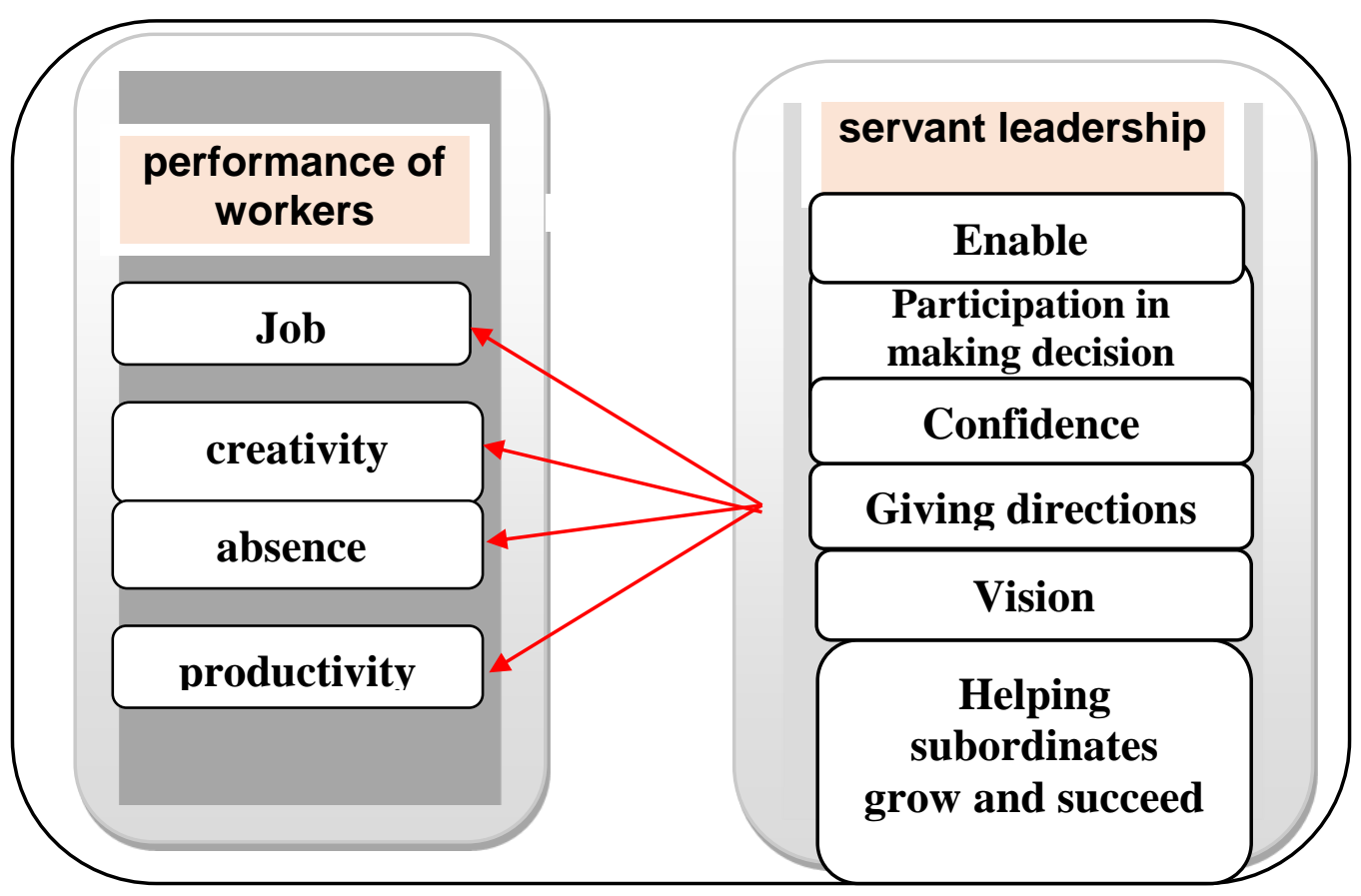

Fig 1. The Study model.

\subsection{The study Community and Sample}

The researchers chose the University of Basra as a community for the study, and it was determined in light of the researchers' inventory of several faculties that serve the objectives of the study, taking into account the diversity in the scientific and human aspects. College of Arts, College of Education for Girls, and College of Law). The following reasons were behind choosing the mentioned colleges:

1. The clarity of the role of leadership patterns in the mentioned colleges as a result of the great role in which Iraqi universities play and their important impact on society, is a service organization, which provides the requirements for advancement in various aspects of life for any country. It is one of the most homogeneous organizations in its activities. Diversity in its sectors of work.

2. This study has adopted the double sample method to obtain the data required for the analysis. The sample included deans, assistant deans, and heads of departments in some faculties of the University of Basra, while the second sample included faculty members in the mentioned faculties. A questionnaire that measures the role of servant leadership in improving the performance of employees was distributed to faculty members. The 
researchers distributed (80) forms to the respondents in their workplaces, and the retrieved and valid forms for analysis were (60) forms.

\subsection{Methods of Data Analysis and Measurement}

1. Conducting validity tests using factor analysis and testing reliability through Alpha Cranach's to measure the accuracy of sample answers.

2. The normal distribution using statistical methods using the program (SPSS 25. v).

3. Descriptive statistics using (arithmetic mean, standard deviation, relative importance).

\section{Servant Leadership Concept}

Servant leadership is one of the contemporary theories in organizational behavior, which has a positive impact on the behavioral patterns of employees, such as job satisfaction, job commitment, organizational confidence, organizational culture, empowering workers, so we can clarify several concepts from the point of view of several researchers:

Olesia defined servant leadership as ((a leadership style upside down, i.e. the leader who transcends his interests and prefers serving the needs of others, as it helps them achieve growth and development and allows them to achieve what they aspire to financially and emotionally, taking into account the work to achieve the goals of the organization)).[1] (as mentioned by Northouse) as it is the relationship between the leader and the follower, and it is one of the forms of moral leadership because it reflects the aspect of privileging others over the self and what is known about its concerns with the needs of subordinates and its focus on moral considerations in the relationship of the leader with his followers who are in power And the end of that relationship is [2]. And Blanchard shows that servant leadership means influencing people so that they participate willingly and voluntarily in the pursuit of common goals beneficial to all parties with all their hearts, minds, souls, creativity, excellence, and all other resources they possess[3] While Patterson sees (the concept of servant leadership by focusing on the relationship between the leader and the follower, it is a type of leadership that requires focusing on the followers first and foremost [4. ]From the foregoing and after reviewing the researchers' views, it becomes clear that the concept of servant leadership is a strategy and a model of work through the positive influence of the leader on the behavior and organizational culture of workers to change their attitudes and help them achieve their interests without any conflict with the interests and objectives of the organization as a whole through altruism, sacrifice, humility and achieving trust among them. Justice and equality.

\subsection{Dimensions of Servant Leadership:}

There is a discrepancy in the views of researchers about the dimensions of servant leadership, which differ according to the field and nature of work. Most of the dimensions agreed upon by all researchers were chosen, which may bear different names, but they carry the same content, which is as follows:

\subsubsection{Confidence:}

1. Trust is one of the most important dimensions of servant leadership, which is represented by the leader's high morals and credibility in dealing and implementing 
promises with others, it has a fundamental impact on the relationship between the boss and subordinates, as the lack of trust leads to a negative feeling among employees, which affects their behavior and job performance, and from an organizational perspective, trust can be defined It is any behavior in a way that makes professional roles secondary when the individual is a leader, where confidence revolves around selfhonesty and is accurately represented, privately and publicly, in the leader's internal intentions and commitments towards followers [5]

2. Al-Atwi \& Al-Shaibani consider (it is the positive feeling that the individual possesses towards the other party in terms of his confidence in carrying out the agreed actions and actions, and it can be said that it is a mental state that cannot be measured directly and cannot be verified at present, but it is possible to see its results in the future, and it can be measured by behavior, which is A movement that includes voluntary work between two people, so the first must show his confidence for the other party to trust him, otherwise the two will remain distrustful of each other, the concept of trust is one of the most important concepts that is difficult to define without research and scrutiny, as it represents a basic element for organizations of all kinds)[6] .

\subsubsection{Participation in Decision-Making}

Participation in decision-making The decision-making process goes through several stages, and the process of employee participation in the decision-making process is the most important stage by motivating workers and giving them self-confidence and power to make decisions. It is psychological, political, economic, and social, and therefore the decision-making process is carried out through teamwork, and therefore we find that the decision-making process includes all the stages before the issuance of the decision, including the final stage. [7]

\subsubsection{Empowerment}

Empowerment is one of the basic characteristics of servant leadership, as it is based on a basic idea that (the authority to make decisions must be delegated to employees to enable them to respond effectively to the needs of customers. This idea in its previous sense forces the leadership to abandon its old method based on the idea of guidance and adopt a new method based on consultation and participation[8]. Empowerment is closely related to the previous dimension, with the leader empowering and developing workers in several aspects, including training, creativity in the field of work, information exchange, self-confidence, and decisionmaking, each according to his work.

\subsubsection{Vision}

All organizations begin their work by setting a clear vision to achieve their strategic goals, which are laid by leaders mainly and their abilities to succeed in communicating these visions and influencing the trends and behavior of employees to achieve the goals of the organization. And (Russell) sees that The most important thing that distinguishes a servant leader from others in terms of a sense of the unknown and the ability to provide a strategic vision for the organization and make others believe in his abilities to predict what is difficult to predict to achieve the desired goals[9]. We also find that the success of leaders depends on their vision of their 
organizations, as well as the ability of leaders to formulate a good vision that positively affects their ability to influence workers.10]

\subsubsection{Giving Directions}

These are the characteristics that affect the workers and that the servant leadership seeks by providing the necessary support and guidance in how they perform their work, which is concerned with developing their efficiency to achieve their goals, which are aimed at achieving goals of the organization. Therefore, Abdullah believes that the servant leader should provide directions and instructions to subordinates to be Introducing them to what is required of them and what is beneficial to both the workers and the organization, as well as making the tasks move dynamically towards achieving the goals of the organization, and from this direction, providing directions means providing a degree of health for the issue through which the servant leader can push his subordinates to work with high-quality performance and to the maximum of their energies in A framework through which to satisfy their needs and desires and achieve their personal goals of servant leadership.[11].

\subsubsection{Helping Subordinates Grow and Succeed}

The human resource is one of the most important assets of organizations in its various specializations and sectors, and it has a significant impact on its success and progress. Therefore, leaders of organizations should pay attention to workers, appreciate their support for them, facilitate their tasks and satisfy their needs.[12] a believes that the servant leader for subordinates is a present and future value in sound organizations and the leader expresses his responsibility to take care of others towards achieving their full potential. Individuals can be developed in any organization by creating a dynamic learning environment as the mistakes of others lead to a vision new and are viewed as learning opportunities[13] .

\subsection{Employees Performance}

The best way to achieve the goals of the organization is to raise the performance of the individual worker by providing appropriate conditions for the nature of work, and the most important of these conditions is the nature of the interaction between the leader and subordinates (administrative behavior) because it is the most interactive relationship than the workers' dealing with other things such as machines, equipment or other things. Such as administrative, marketing ells. (Russell) defined the performance of workers in organizations as (the set of managerial behaviors that express the individual employee's performance of his work, which includes the quality and level of performance, capabilities, and skills required such as communication skills and interaction with the organization's customers and the extent of commitment to and response to administrative systems[14] that the performance of employees refers to all behaviors that contribute to the completion of basic work in the organization, such as production and marketing, and it is possible to identify sub-paragraphs through which it is possible to determine the efficiency of the performance of employees in any organization as follows:

\subsubsection{Job Satisfaction}


Job satisfaction is meant the positive feeling that employees feel towards the leader and the organization, which leads to outstanding performance as a result of what the organization offers them. Therefore, job satisfaction has been defined as the degree of positive or negative feeling of members of the organization towards their work and tasks in the organization [15] The job satisfaction is explained as the pleasant psychological or emotional state that the working individual reaches when he attains a certain degree of satiation. Therefore, it is the responsibility of the organization to encourage them and their participation in the various affairs of the organization, such as allowing their participation in defining job descriptions and limits, contributing to the performance evaluation procedure, and participating in decision-making. A distinguished organization values its employees and allows for mutual benefit to be achieved between the organization's goals It also develops the employees' capabilities to promote justice and equality[16.]

\subsubsection{Creativity}

Creativity is meant to generate and develop new ideas to benefit from them in the performance of employees, and there is a set of definitions of creativity, as[17]sees that creativity means the application of a good idea as a beginning or improvement of a product, process or service, and explain[18] that creativity is a complex process that is easy to identify as being of fundamental importance in achieving organizational success, but it is difficult to manage it. If the international competition intensifies and the product life cycles are shortened, the pressure on the necessity of creativity multiplies, and thus creativity means renewal as it depends mainly on initiative and starting from ideas and knowledge. New and innovative things are created that were not previously through interaction and blending, so creativity is a process characterized by it When the individual encounters situations, he gets excited and experiences them deeply, then responds to them in a manner consistent with himself, the response is different from the response of others and is singular. This process includes service products, technologies, new work, new administrative tools, and processes, or new ideas methods. Here, the organization's management must adopt a policy that Motivates and encourage appropriate development of creativity and help invest the energy of talented by providing the appropriate atmosphere for them at all levels.[19].

\subsubsection{Absence}

Absence is the worker's failure to attend work at the time he is expected to attend to participate in the production according to the work program. If the person is on an official vacation or Holiday, this is not considered an absence, even if this situation reduces the number of people available to work, the lesson is the person's absence To work even though he is restricted in the work schedule [20]

\subsubsection{Productivity}

The improvement in productivity in terms of quantity, type, and cost occur if one of the following indicators is achieved (increasing outputs while remaining the same inputs, reducing outputs by less than the proportion of reducing inputs, increasing outputs by a greater proportion than increasing inputs, obtaining the same outputs but with fewer inputs)[21] As some researchers see, the high performance of the organization is achieved through the interaction of five main components:(employee involvement, self-directed team, total quality management, organizational education, integrated production technology[22] in the framework presented. 
The active role of servant leadership with all its variables and its direct impact on the individual worker, considering it the most important input to productivity and performance, is one of the basics necessary to achieve any success and high efficiency.

\section{The Practical Side}

In this topic, the information resulting from the analysis of the data collected using the questionnaire designed in the light of the five-point Liked scale will be interpreted, their subdimensions and to test the study hypotheses using descriptive statistics methods and inferential.

\subsection{Questionnaire Validity Test (Reliability and Validity)}

The reliability test was conducted by the (half-splitting) method to know the stability value of the questionnaire (the scale), which means the stability of the results obtained (that the scale gives the same results if it is re-applied), and also the validity was tested by the (selfauthenticity) method to know the validity of the scale Which means does the scale measure what it is designed to measure (how well the test represents the behavior to be represented).

Table 2. Shows the values of the reliability and validity coefficients for the scale.

\begin{tabular}{|c|c|c|}
\hline Dimension/Variable & $\begin{array}{r}\text { Stability coefficient } \\
\text { value split half }\end{array}$ & $\begin{array}{c}\text { The value of the self- } \\
\text { honesty coefficient } \\
\text { )square root of stability } \\
\text { coefficient( }\end{array}$ \\
\hline Servant Leadership & 0.90 & 0.94 \\
\hline Employee performance & 0.87 & 0.93 \\
\hline Total Scale (Resolution) & 0.91 & 50.9 \\
\hline
\end{tabular}

It is clear from the values of the reliability coefficients above that all of them are greater than (0.67), and therefore the scale is characterized by high stability, and the values of the selfhonesty coefficient were high and close to the correct one, which indicates that the scale is characterized by acceptable honesty and stability and is suitable for relying on the outputs obtained from it.

\subsection{Characteristics of the Study Sample (Demographic Information)}

In this paragraph, we show the characteristics of the demographic study sample, which includes (gender, age, years of service in the job, academic achievement) and as in the following table:

Table 3. Demographic Information.

\begin{tabular}{|c|c|c|c|}
\hline $\begin{array}{c}\text { Identification } \\
\text { Information }\end{array}$ & Categories & Frequency & Percentage \\
\hline \multirow{2}{*}{ Gender } & Male & $\mathbf{3 0}$ & $\mathbf{\% 5 0}$ \\
\cline { 2 - 4 } & Female & $\mathbf{3 0}$ & $\% 50$ \\
\hline \multicolumn{2}{r|}{ Total } & $\mathbf{6 0}$ & $\% 100$ \\
\hline
\end{tabular}




\begin{tabular}{|c|c|c|c|}
\hline \multirow{4}{*}{ Age } & year $20-25$ & 18 & $\% 30$ \\
\hline & year26 -30 & 14 & $\% 23.3$ \\
\hline & 35 year 31- & 16 & $\% 26.7$ \\
\hline & More than40 year & 12 & $\% 20$ \\
\hline \multicolumn{2}{|c|}{ Total } & 60 & $\% 100$ \\
\hline \multirow{4}{*}{$\begin{array}{c}\text { years of service in } \\
\text { the job }\end{array}$} & 5years or less & 18 & $\% 30$ \\
\hline & 6-10 year & 12 & $\% 20$ \\
\hline & 11-15 year & 16 & $\% 26.7$ \\
\hline & More than 15 year & 14 & $\% 23.3$ \\
\hline \multicolumn{2}{|c|}{ Total } & 60 & $\% 100$ \\
\hline \multirow{4}{*}{ Achievement } & Bachelor & 16 & $\% 26.7$ \\
\hline & Higher Diploma & 14 & $\% 23.3$ \\
\hline & M.A. & 16 & $\% 26.7$ \\
\hline & PhD & 14 & $\% 23.3$ \\
\hline \multicolumn{2}{|c|}{ Total } & 60 & $\% 100$ \\
\hline \multicolumn{4}{|c|}{ Source: Prepared by researchers based on the outputs of the spss v25 program } \\
\hline
\end{tabular}

Through the above table, it is clear that the characteristics of the research sample were representative of the male and female categories in equal proportions, while the years of service in the job for all groups were in close proportions for the researched sample, which means that there is a good diversity in the members of the selected sample that will give good perceptions to achieve the goal of the study. The ages of the selected study sample were medium and close for all groups. As for academic achievement, the highest percentage of holders of a bachelor's degree and a master's degree was in equal proportions, amounting to $(26.7 \%)$, while it was for holders of doctorate degrees and higher diploma in equal percentages also at a rate of (23.3\%), which are all percentages They are close, indicating that the scientific level of the study sample includes multiple categories that will give greater credibility to its outputs.

\section{3-3-Sample trends about the study variables and their sub-dimensions}

To know the trends of the sample members about the research variables and their subdimensions, the researchers used for this purpose the weighted arithmetic means, standard deviations, and the relative importance (agreement ratio) to measure and evaluate the degree obtained related to the responses of the study sample members, to identify the extent of consistency and compatibility in the opinions of the sample and their perceptions of variables The study, in general, is as follows: Perceptions of the sample members about the independent variable (servant leadership) and its dimensions:-The servant leadership variable was measured with six sub-dimensions including (trust, participation in decision-making, empowerment, vision, providing guidance, helping subordinates to success and growth) and each dimension consisted of several paragraphs (questions) included in the study questionnaire and the statistical outputs were as in the table following: 
Table 4. Shows the responses of the sample members and their perceptions of servant leadership and its sub-dimensions.

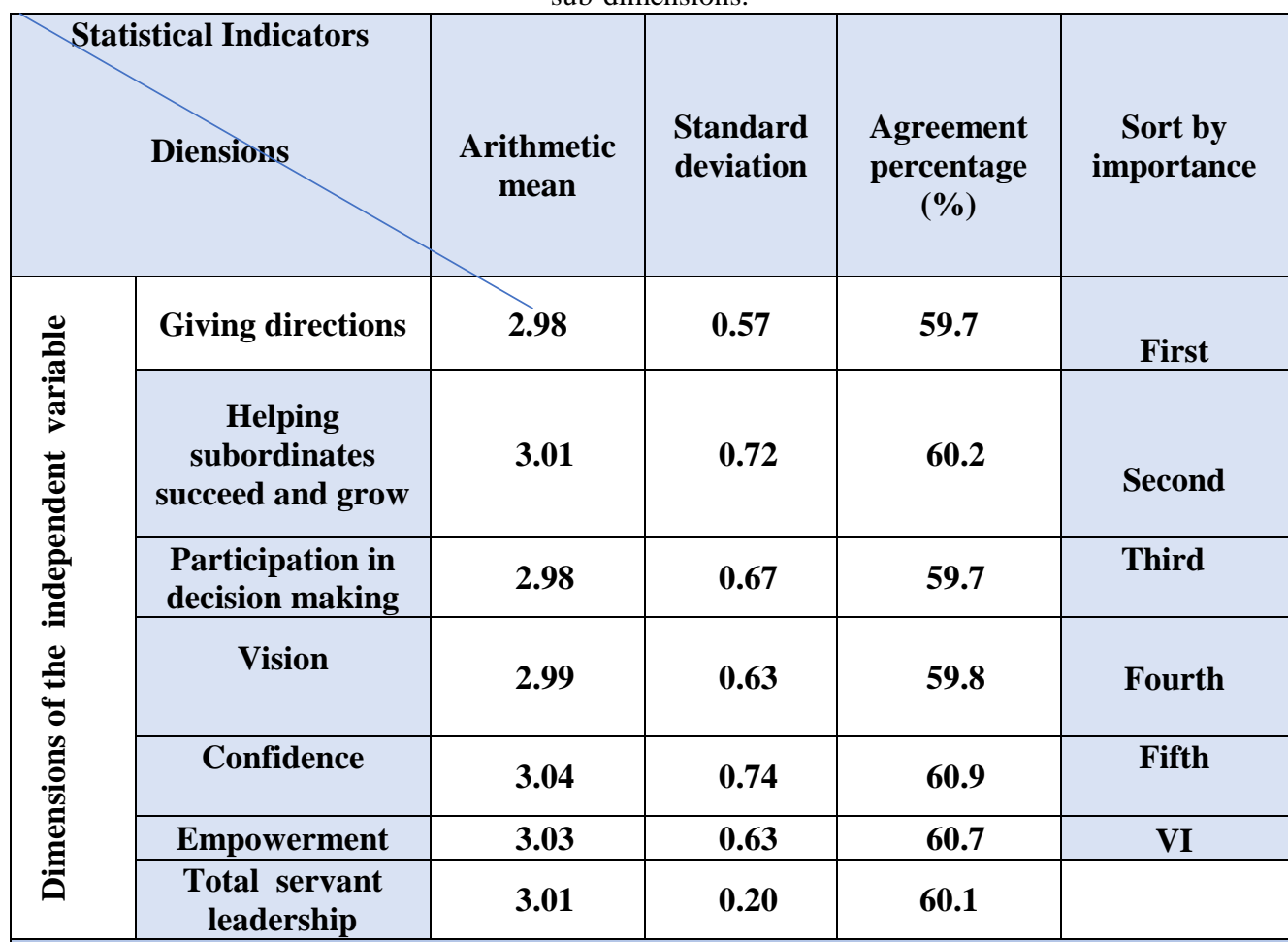

Source: Prepared by researchers based on the outputs of the spssv25 program

1. Evident from the above table that the percentage of agreement among the study sample members is very close to the dimensions of the servant leadership variable, and it was arranged according to the arithmetic mean (trust, participation in decision-making, empowerment, foresight, providing guidance, helping subordinates to success and growth) respectively, where the percentage of agreement was (The relative importance) for each of them is about (59\%-60\%), which is an agreed percentage indicating close importance to the study sample for all dimensions of the independent variable, and the arithmetic mean values of the servant leadership variable and its dimensions indicate a neutral trend when classified on a five-graded Liked scale, and that their answers This is evident from the small standard deviation value, where all dimensions were less than one.

2. The sample members' perceptions of the dependent variable (workers' performance) and its dimensions:

a) The employee performance variable was measured with four sub-dimensions including (job satisfaction, creativity, absence, productivity) and each dimension consisted of several paragraphs (questions) included in the research questionnaire form and the statistical outputs were as in the following table: 
Table 5. Shows the responses of the sample members and their perceptions of the employees' performance and its sub-dimensions.

\begin{tabular}{|c|c|c|c|c|c|}
\hline & $\begin{array}{l}\text { Statistical } \\
\text { Indicators }\end{array}$ & $\begin{array}{l}\text { Arithmetic } \\
\text { mean }\end{array}$ & $\begin{array}{l}\text { Standard } \\
\text { deviation }\end{array}$ & $\begin{array}{c}\text { Agreement } \\
\text { percentage } \\
(\%)\end{array}$ & $\begin{array}{c}\text { Sort by } \\
\text { importance }\end{array}$ \\
\hline \multirow{5}{*}{ 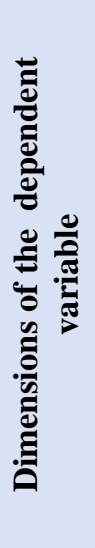 } & Productivity & 3.12 & 0.69 & $62.3 \%$ & First \\
\hline & Creativity & 3.06 & 0.52 & $61.2 \%$ & Second \\
\hline & Absence & 3.04 & 0.48 & $60.8 \%$ & Third \\
\hline & Job Satisfaction & 3.06 & 0.58 & $61.2 \%$ & Fourth \\
\hline & $\begin{array}{l}\text { total employees } \\
\text { performance }\end{array}$ & 3.07 & 0.38 & $61.4 \%$ & \\
\hline
\end{tabular}

Source: Prepared by researchers based on the outputs of the spssv25 program

Evident from table (4) above that the percentage of agreement among the study sample members is very close to the dimensions of the variable performance of employees, and it was arranged according to the arithmetic mean (productivity, creativity, job satisfaction, absence) respectively, where the percentage of agreement (relative importance) for each of them is about ( $60 \%-62 \%$ ), which is an agreement percentage indicating close importance to the study sample for all dimensions of the dependent variable, and the arithmetic mean values of the variable performance of workers and its dimensions indicate a neutral trend when classified on a fivegraded Liked scale, and that their answers are homogeneous on these dimensions, and this is evident from the value of little standard deviation where all dimensions were less than one.

\subsection{Measuring, Testing, and Analysing the Correlation and Effect Relationships Between the Study Variables (Testing the Study Hypotheses)}

To test the hypotheses of the study, the researchers used inferential statistics methods (normal distribution test, linear correlation, Pearson coefficient, simple linear regression) as follows:

\subsubsection{Normal Distribution Test}

Conducting the statistical analysis of the data requires the availability of certain conditions, the most important of which is the normal distribution of the data. The (Kolmcrof-Smirnov) test and the (Shapiro-Wilk) test have been conducted for the independent variable and the dependent variable, where the null hypothesis that indicates a normal distribution of data is tested against the alternative hypothesis that indicates The data does not follow a normal distribution, as shown below: 
Table 6. Shows the results of the Kolmcrof-Smirnov (K-S) test and the (Shapiro-Wilk) (S-W) test for a normal distribution.

\begin{tabular}{|c|c|c|c|}
\hline Variable & $\begin{array}{c}\text { Sample } \\
\text { size } \\
\text { (n) }\end{array}$ & $\begin{array}{c}\text { (Kolmcrof-Smirnov) test } \\
\text { (K-S) }\end{array}$ & $\begin{array}{l}\text { (Shapiro-Wilk) test } \\
\text { S-W)( }\end{array}$ \\
\hline $\begin{array}{l}\text { X:Servent } \\
\text { leader ship }\end{array}$ & \multirow{2}{*}{60} & $.101 * * 0$ & $.968 * * 0$ \\
\hline $\begin{array}{l}\text { Y: employees } \\
\text { performance }\end{array}$ & & $.162 * * 0$ & $0.933 * *$ \\
\hline \multicolumn{4}{|c|}{$\begin{array}{l}\text { The mark }(* *) \text { indicates that the test value is significant assuming a level of } \\
\text { significance }(0.01) \text {, meaning that the }\left(P_{-} \text {value) is greater than }(0.01) .(\right.\end{array}$} \\
\hline
\end{tabular}

Through the above table, it is clear that the independent variable and the dependent variable follow a normal distribution, where the null hypothesis is accepted, which indicates that the data follow a normal distribution where the (P_value) of the two tests above was greater than $(0.01)$ and the histogram below shows the curve of the normal distribution of the two variables:

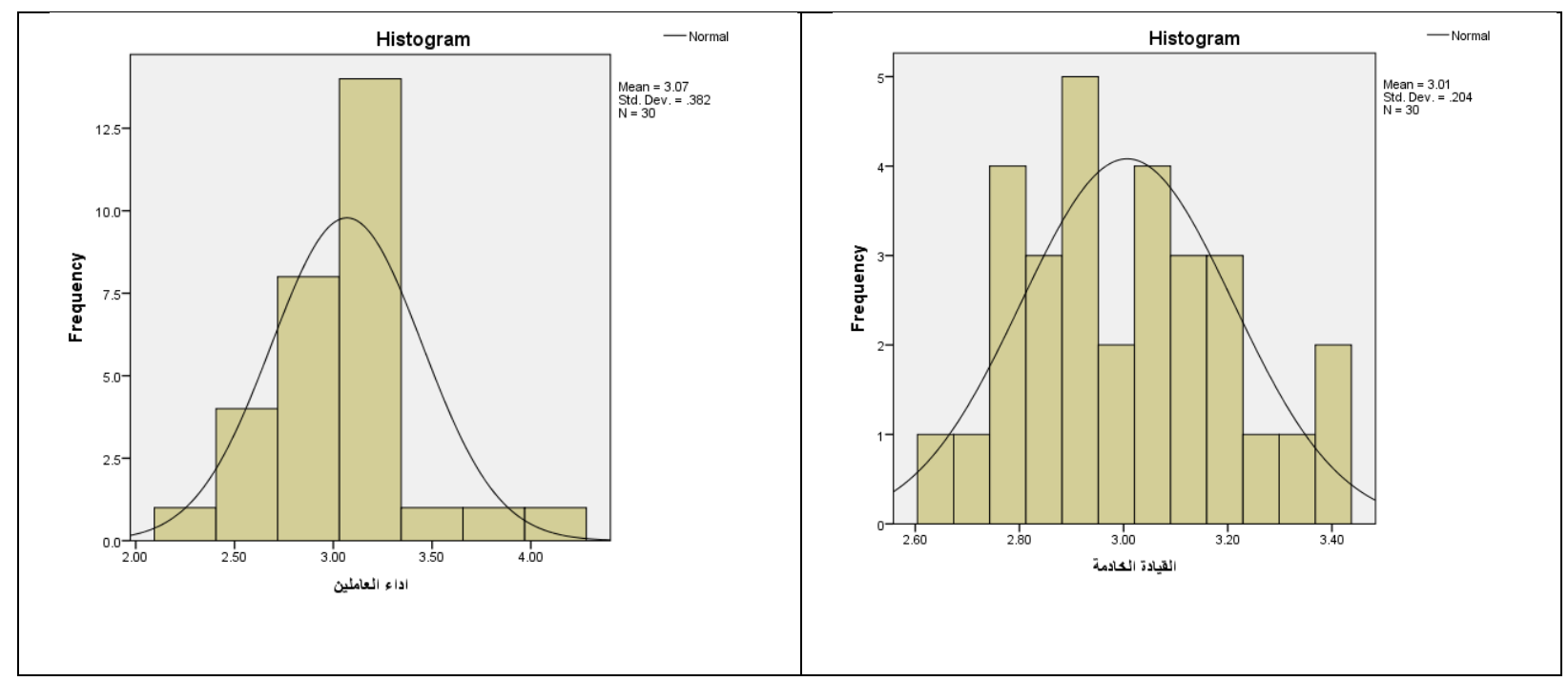

Fig 2. Normal Distribution Curve.

\subsubsection{Testing the Existence of a Correlation Between the Research Variables}

To test the first hypothesis which states (there is a positive statistically significant correlation between servant leadership and the performance of employees at the University of Basra), the simple linear correlation coefficient was calculated between the variable (servant leadership) and the variable (worker performance) as in the table below: 
Table 7. Correlation coefficient (Pearson) between research variables.

\begin{tabular}{|c|c|c|}
\hline $\mathbf{Y}$ & $\begin{array}{c}\text { Employees } \\
\text { performance: } \mathbf{Y}\end{array}$ & p-value \\
\hline X:servent leadership & $* * 0.77$ & 0 \\
\hline
\end{tabular}

The sign (**) above the value of the correlation coefficient indicates that the correlation is significant (statistically significant) assuming a level of significance $(0.01)$, meaning that the $\left(P_{-}\right.$value) of the $(t)$ test is less than $(0.01)$

Source: Prepared by researchers based on the outputs of the spss v25 program

It is clear from the above table that the correlation between servant leadership and the performance of employees is significant (statistically significant) below the level of morality (0.01), which is a direct (positive) and strong correlation, which means that the first hypothesis is accepted and that the increase in the presentation of the servant leadership model in Basra university institutions will cause an increase in performance staff.

\subsubsection{Testing the Existence of an Effect of the Independent Variable (Servant Leadership) on the Dependent Variable (the Performance of Employees)}

To test the second hypothesis which states (there is a positive and statistically significant effect of servant leadership on improving the performance of employees at the University of Basra), a simple linear regression analysis was used to determine whether the independent variable (servant leadership) affects the dependent variable (the performance of employees) and what is the size of the effect. As in the table below:

Table 8. Test values (F), coefficient of determination (R2), and regression coefficients.

\begin{tabular}{|c|c|c|c|c|}
\hline \multicolumn{5}{|c|}{ Y: employees performance } \\
\hline $\mathbf{X}$ & $\begin{array}{c}\text { value }(\mathrm{F}) \\
\text { Calculated }\end{array}$ & $\begin{array}{l}\text { Coefficient of } \\
\text { determination } \\
\qquad) \mathbf{R}^{2}(\end{array}$ & $\begin{array}{l}\text { Regression } \\
\text { constant (A) }\end{array}$ & $\begin{array}{c}\text { Regression } \\
\text { coefficient (B) }\end{array}$ \\
\hline $\begin{array}{l}\text { X:servent } \\
\text { Leadership }\end{array}$ & $33.45 * *$ & $\% 60$ & 2.21 & 90.4 \\
\hline \multicolumn{5}{|c|}{$\begin{array}{l}\text { The sign }(* *) \text { with the highest value }(F) \text { indicates that the effect is significant } \\
\text { (statistically significant) assuming a level of significance }(0.01) \text {, meaning that the } \\
\text { (P_value) is less than }(0.01) \text {. }\end{array}$} \\
\hline \multicolumn{5}{|c|}{$\begin{array}{l}\text { The significance of the regression model is tested through the value (F), while the value } \\
\text { of the coefficient of determination (R2) represents the explanatory power of the } \\
\text { independent variable for the changes that occur in the dependent variable. }\end{array}$} \\
\hline
\end{tabular}


There is a significant effect (statistically significant) below the level of significance (0.01) for the servant leadership variable in the variable of employee performance. The servant leadership variable explained about $(60 \%)$ of the changes that occur in the performance of workers, and the rest is due to other variables and the random error factor, which means accepting the second hypothesis. And that the performance of employees is improved by applying the servant leadership model in the institutions of the University of Basra. The regression equation of the dependent variable (the performance of the workers) on the independent variable (the servant leadership), which was equal to: (the performance of the workers $=2.21+0.49$ of the servant leadership). ), and in the case that the servant leadership is equal to zero, the renewal of the performance of the workers will be equal to (2.21).

\subsubsection{Discussing the Results}

1. The majority of the sample members agreed with the availability of the elements of servant leadership in the colleges under study, but there is a lack of interest in some important aspects of the dimensions of servant leadership represented in ((trust, participation in decision-making, empowerment, vision, providing guidance, and helping subordinates to succeed and grow)). This generates a feeling of dissatisfaction and injustice, which may push the workers to take other aspects of work called informal organizations, which may conflict with the directions of the management

2. Most of the sample members agree that there is no real desire on the part of the senior management to formwork teams and encourage workgroups because they believe that assigning such an approach will reveal problems and provide solutions that the higher management may not understand, or it may consider it an additional failure that weakens its authority.

3. It was also shown that the senior management in the college's understudy was not aware of such leadership patterns and its impact on identifying the problems and tendencies of the workers, as the worker is a person with feelings and interests, which are closely linked with his colleagues and with the external environment that cannot be separated from them, which indicates the lack of understanding of the higher management aspects Psychological and social, which works to organize the relationship of the individual with others so that he can perform his tasks in achieving his goals and the goals of the organization together

4. The presentation and analysis showed the validity of the hypothesis (there is a positive and statistically significant effect of servant leadership on improving the performance of employees at the University of Basra).

\section{Conclusions and Recommendations}

As a result of the indicators of the study, the following conclusions were reached:

1. The results showed the presence of the constituents of servant leadership in the sample under study, in addition to the existence of a correlation and an effect for the two variables (independent and dependent) in some university formations, whether at the macro or sub-level.

2. The emergence of a significant and positive effect of the two main variables 
3. The working individuals are instinctively inclined to form relationships with colleagues and superiors through which they seek to achieve their goals

4. The servant leadership style focuses on the positive psychological aspects by raising individual motives in addition to focusing on the material aspects by identifying the interests of the workers - and working to achieve them - which are mostly material rather than psychological or social, which all lead to improving the performance of workers.

5. The realization of the faculty members in the faculties of the University of Basra that the leadership vision is a distinctive characteristic of its leadership.

6. The results of the study show that the leaders' orientation towards establishing teamwork with its various practices, as well as the issue of providing the opportunity for others to participate in decision-making was at a weak or not prominent level, and this simply explains the absence of some trends and practices that are emphasized in the management literature regarding strengthening the teamwork process within organizations.

7. It is clear from the practical side that the percentage of agreement among the study sample members is very close to the dimensions of the servant leadership variable, and it was arranged according to the dimensions (trust, participation in decision-making, empowerment, vision, providing guidance, helping subordinates to success and growth), which indicates a positive and influential trend Which leaders work in the faculties understudy

8. As it is clear that the percentage of agreement among the study sample members is very close to the dimensions of the employee performance variable, and it was arranged according to the arithmetic mean (productivity, creativity, job satisfaction, absence), respectively, where the percentage of agreement was average, which is an agreement percentage indicating close importance to the study sample for all dimensions of the dependent variable.

9. The values of the arithmetic means indicate the variable performance of workers and its dimensions.

We recommend decision-makers in the college's understudy to invest their energies and expertise and to move towards adopting the servant leadership style.

1. Spreading the spirit of cooperative work among employees by placing servant leaders in the college's understudy on the one hand and adopting work teams, which creates a positive feeling of belonging and loyalty to those teams, which leads to raising the performance of organizations and achieving their goals.

2. Consolidating the concept of service and sympathy among employees within the university in a way that creates a conducive atmosphere for service and personal assistance towards each other.

3. Adopting the concept of servant leadership as it is one of the most popular leadership styles in encouraging followers and helping them to learn, develop and adopt the philosophy of continuing education, which positively and directly affects the performance of employees. 
4. There must be an awareness for the senior management of the positive impact of servant leaders on the performance of employees and achieving success and development. Therefore, it must start with planning and the correct selection of leaders, and the preparation of servant leaders on a scientific basis.

5. It was found through presentation and analysis that there is a weak relationship between participation and providing guidance, which made there a need to focus on the importance of the participation of employees until a balance is achieved between leadership and subordinates within the organizational environment.

\section{References}

[1]-Olesia weeks s. \& namusonge G.s. \& iravo. Mike "Role of servant leadership on organizational commitment: An Exploratory survey of state corporation in Kenya"International Journal of Humanities and social science. 2013 . Vol 3. N.13 p87

[2] -Northouse, P. G "Leadership: Theory and practice" (Fourth ed.), Thousand Oaks: Sage Publications. 2001. p257

[3]-Blanchard h, K, Relections on encourage the hert .in J. M.Kouzes ,\&B.Z.poster (Eds.)Christian" reflections on the leadership challenge" sanfrancisco. Jossey -Bass .2004. p33

[4]-Patterson, K." A servant leadership A theoretical model (Doctoral dissertation, Regent university retrieved from proQuest Digital Dissertations Databas. 2003. p2

[5]Peterson C., \& Seligman, M. E. Character strengths and virtues: A handbook and classification Oxford University Press. 2004. Vol. 1. p112

[6] - Al-Atawi, Amar and Al-Shaibani, the important "the role of leadership support and trust in building organizational commitment for workers", an exploratory research, the opinions of a sample of employees of the General Directorate of Karbala Education, Karbala University Scientific Journal. 2010. Issue 3 Vol 2 . p131

[7]- Al-Aghbreen, "The Contemporary Planning and Organizational Dimension" Beirut, Dar Al-Nahda Al-Arabiya. 2000. p167

[8]-Adams. s"The relationships among adulf attachment" general self-disclosure. and perceived organizational trust. unpublished dissertation of doctor of human development. faculty of the Virginia polytechnic Institute and state University. 2004. p51

[9] Russell .R.F.\& Stone ,A,G, A" review of servant leadership "attributes leadership \& organization Development Journal .(2002) 23(3/4)p157-145)

[10] -Joseph, E. E., \& Winston B. E.). A correlation of servant leader ship trust, and organizational trust. Leadership \& Organization Development Journal(2005.vol 26.1.p 6-22

[11]-Abdullah, Ron Faridoun " The role of servant leadership in achieving job engagement" An analytical study of the opinions of a sample of faculty members at the University of Sulaymaniyah. 2018. Issue.1.vol (8) p9

[12] -Liden. Robert c, Wayne. S. j, zaho. Hao \& Henderson. D, "servant leadership: Development of a multidimensional measure and multi-level Assessment", leadership Quarterly. 2008. V.19, N.2 p16

[13] Spears Larry (2005). The Understanding and Practice of Servant, studies .regent university

[14]- confirmed Gibbs, John "Performance Measure Properties and Incentives- Institute for the Study of Labor. (2004). No.(1356). On Line, Available at:" www.alazhar.edu.ps/library/aattachedFile.asp

[15]-Schermerhon, Jr, John.R. and James G. Hunt \&Richard N; Os Born".Organizational Behavior"7ed.New York Wiley \&sons. 2000. INC,p57

[16]- Haddad, Shafiq Ibrahim, Judeh, Mahfouz Ahmed, the extent to which ministries and institutions winning the King Abdullah II Award for Excellence in Government Performance and Transparency achieve a culture of excellence from the point of view of their employees and service recipients, The Jordanian Journal of Business Administration. 2015. Issue 2, Vol 11.p 253-282. 
[17]-Robbins, Stephen. Business. Today: The new world of Business. U.S.A Harcourt College publisher. 2001 .p11

[18] Terziovski ,mile \&Samson. Professor Danny and Glassop, Linda Greating" core competence through the management of organizational innovation". 2001. p24

[19] -Kaplan, Soren \& Winby Stu, ( 2007), "Organizational Models for Innovation Organizational Design that Support Strategic Innovation and Growth,p19 On-Line, Available at:" www.innovationpoint.com

[20]- Cascio, W.F. Managing human resources Productivity, quality of work life. Profits "6 ed, McGrawHill: Boston, MA 2003. p24

[21]- Al-Hamami, Sana Muhammad Rashid Daoud, "Methods of conflict management and their impact on the performance of workers, a master's thesis" University of Baghdad (2006) p24

22-Tarr, D, " The strategic toughness of servant-leadership ", In L. C. Spears (Ed.), Reflections on leadership, How Robert K. Greenleaf's theory of servant-leadership influenced today's top management thinkers. New York.1995. :p7 